\title{
Media channels for personal business media
}

\section{Wolfgang Maass*, Beat Schmid and Wolf-Christian Eickhoff}

MCM Institute, University St. Gallen, CH-9000 St. Gallen, Switzerland

Fax: +4171 2242771

E-mail: wolfgang.maass@unisg.ch E-mail: beat.schmid@unisg.ch

E-mail: wolf-christian.eickhoff@unisg.ch

*Corresponding author

\begin{abstract}
Although the world wide web is already about ten years old, it is still a dream that products and services actively serve user's needs. Central market-places with product catalogue metaphors still dominate the internet. This means that market-place participants are required to access, understand and analyse the available offerings before they can interact with other participants or market-place services. Personal business medias start from the position that channels for product and service offerings can be dynamically grouped around the needs of participants so that new and personalised market-place structures can be designed, i.e. market-places come to me at home and speak my language. In contrast to many other approaches, personal data processing is not hosted by a market-place operator but stays with the user. We argue for the position that personal business media provide means to implement open and modular digital media. Finally with micromarkets a platform is presented which demonstrates how personal business media can be implemented.
\end{abstract}

Keywords: digital media; electronic markets; peer-to-peer.

Reference to this paper should be made as follows: Maass, W., Schmid, B. and Eickhoff, W.-C. (2004) 'Media channels for personal business media', Int. J. Internet and Enterprise Management, Vol. 2, No. 2, pp.139-151.

Biographical notes: Dr Wolfgang Maass studied computer science at the University of Aachen (RWTH) from 1985 to 1990. In 1989 he finished his undergraduate studies. From 1990 to 1992 he studied at the University of Saarbrücken and the German Research Centre for Artificial Intelligence (DFKI). From 1992 to 1996 he made his doctoral studies in cognitive science. In 1994 he was invited to the National Center for Geographic Information and Analysis (NCGIA). From 1997 to 1998, he worked for Diebold Management Consulting. Since 1998 he has been Senior Researcher at the mcm institute at the University of St. Gallen. His major research interests concern the field of digital media, content management systems, knowledge management systems and in particular open source.

Beat F. Schmid is Professor and Managing Director of the Institute for Media and Communications Management MCM at the University of St. Gallen, Switzerland. He has had over 30 years experience in researching the field of information management, knowledge media and communication management 
in the new media. From 1991-95 he was Dean of the BA faculty and from 1993-97 Vice President of the University of St. Gallen. In cooperation with the Bertelsmann Foundation, the Heinz Nixdorf Foundation and the University of St. Gallen he founded the Institute of Media and Communications Management which started research and lecturing in 1998.

Wolf-Christian Eickhoff is a Research Assistant and PhD Student at the University of St. Gallen where he works for the mcminstitute (Institute for Media and Communications Management). He is a member of the Intelligent Media Group. He holds a diploma in electrical engineering from the University of Technology, Aachen, Germany, focusing on technical informatics. His diploma thesis dealt with group communication protocols. In 1996/97 Wolf-Christian spend two semesters at University College, Cork, Ireland.

\section{Introduction}

From a social point of view market-places are transactional and communicational media in which autonomous agents can communicate product designs, negotiate contracts and perform contract executions [1]. Their market behaviour is directed by their intentions (e.g. [2]) and logical representations, such as mental models [3], which are derived before and during interactions with the market-place. The correlated set of sub-languages consisting of symbols and associated meanings constitute the logical space of the market-place [4]. Stock market-places, for instance, require very precise language between traders, brokers and operators. The communicational aspects of the logical space are part of a natural or artificial language which mainly consists of symbols, words, grammar, protocols, and pragmatic rules. Protocols are communicational scripts which describe the roles of interacting actors and the potential paths a communication can take. Communication affects the liquidity of a market-place because the more precise a protocol and associated services are defined, understood, and accepted by all actors in a market-place the better is its liquidity. Europeans typically have major problems in acting efficiently in a Moroccan market-place if they do not understand and share the logical space of the market-place. To act efficiently they have to take locals to translate the market-place, including the underlying protocol, into the language which they use in comparable situations.

The concept of a market-place, as part of a more general media theory, requires a place of interaction where actors in specific roles can interact in order to exchange goods, information, and financial resources [1]. Transactions, but also exchange of information and knowledge, are mediated by communications. In efficient and effective market-places communications are well-established in the sense that key actors share a common logical space sufficiently and know about the communication channels and associated services. Most of the traditional market-places, such as stock exchanges and cattle market-places, are centred in time and space. People come together, take defined roles, and use defined language over communication channels and services to act on the market-place. With the rise of telecommunicational infrastructures globalisation was introduced so that market-places became independent of time and space. In global, mediated market-places a clear understanding by all market participants of the underlying organisation, language, communication channels and associated services became even more important ([4-7]). 
As we will discuss later, the world wide web (www) provided the prototype for most of these market-places. The major paradigm behind digital market-places in the www is that the provider of information defines the organisation and the language and superimposes this on all other participants. This paradigm is a transfer of traditional marketing theories (e.g. [8]) and traditional market-place structures, such as stock market-places. Traditional marketing theories describe the process of translating market messages of consumers by the concept of perception. It includes 'the process by which people select, organise, and interpret information to form a meaningful picture of the world' (see [8] p.132).

But as Moran already indicated, products should be presented in a frame or 'mental presence' that is recognised by a buyer, such as a consumption or purchase situation [9]. A product has a greater chance of being understood if the situation in which it is presented is one that is expected and relevant to the buyer [10]. This position goes beyond the traditional behavioural marketing perspective which mainly ignores the active role of agents in the translation process of market-place-based communication (e.g. [11]).

Hence, the gain of traditional electronic market-places is the extension of existing businesses into digital media. But the question is which potentials are to be unleashed. In this article, we will discuss the concept of personal business media by which market messages are interpreted in the language of market participants. We will discuss requirements for corresponding architectures of personal business media.

\section{Electronic markets}

In the traditional business media model, electronic markets are seen from the perspective of the place of interaction. One dominant design element of electronic market-places is that buyers, sellers, and other participants go there and access it before they can act. The underlying metaphor is that of a central, physical market-place where all market participants meet. Technologically this fitted very well with design criteria of client-server architectures. Therefore servers are synonymously matched with a market-place and clients with market-place participants. Following Grieger [12], electronic market-places can be seen as an interorganisational information system [13], an electronic procurement solution [6], a medium [5], a meeting point [14], an intermediary [15] or just a listing [16].

In the following, we will base our analysis on the media model developed at the MCM Institute, University St. Gallen [5] which guides our analysis and design of communities and their media, of business models and system architectures, and of communication and service designs.

Electronic markets can be viewed as Business Media [5]. This is a holistic approach that brings together technological, communicational, business, and managerial issues. Business Media are considered as transaction-based media providing the means for the creation and exchange of values like goods and services between independent agents. Four kinds of communication acts are distinguished: in the information phase, agents exchange information and they establish their knowledge or belief. In the intention phase, agents signal intentions, developed from the knowledge provided in the knowledge phase and by the linguistic means of the common logical space, following their role and the protocols. In the contracting phase, agents negotiate contracts. Messages in this phase are binding, in the sense that they oblige agents to act as indicated. This phase ends - in 
the case of success - with a contract. In the settlement phase, agents act according the negotiated contract. In commerce, this means for instance shipping of goods and transaction of money.

Media are considered as multi agent systems (see Figure 1), which consist of a channel system for the transport of information over space and time, a logic, for capturing syntax and semantics of the information and an organisational system (roles and protocols) for structuring the behaviour of its agents. Hence a market-place consists of:

- the provided channels for interaction in a market-place

- the logical space by which messages are decoded

- the organisation which determine the roles, organisational structures, and processes [17].

Market-places can be characterised by their language and by their underlying technical infrastructure. The language is either defined by the operator or by the participants, i.e. users. Mixed forms are also in use. The technical infrastructure is either centralised in a client - server logic or decentralised by peer-to-peer-based infrastructures.

Figure 1 Media model

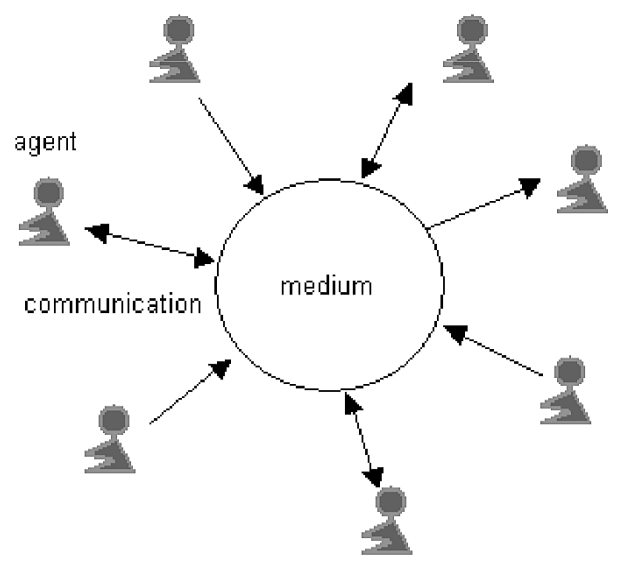

Traditional electronic market-places are typically operator-driven (maxim: 'who pays, controls') with a central client - server infrastructure, e.g. COVISINT for automotive supply chain management. Some market-places implemented personalisation techniques with the goal to adapt services to the user. These types of personalisation only addressed the selection of service channels and filtering of content but not a transformation of the content itself. These market-places can be seen as weak forms of market-places with user-driven logical spaces and centralised infrastructures. Decentralised infrastructure re-appeared with Napster and Gnutella. Both are examples for a non-commercial, operator-driven market-place. They are based on an operator-driven logical spaces and one protocol for each. Market-places which adapt to users in language and services can be implemented by peer-to-peer infrastructures. Ancient forms of monarchies can be seen as instantiations of those models. The queen, i.e. the peer, sits in her castle and selects from services and goods which are presented in her language. The market-place is 
completely adapted to her but is decentralised because any producer is more or less independent in his production system. The drawback of this market-place design is a poor liquidity. If you sell to the queen you are in business otherwise you have problems with selling your services and goods.

Personal business media assume that any user is perceived as a queen or king. Because anybody can become a queen or king the potential of liquidity in personal business media will rise even above the liquidity in operator-driven market-places.

\section{Central and decentral models for electronic market-place}

As discussed, market-places are places of interactions which are used to exchange solutions. The better a participant can act and interact in a market-place the better she understands the organisation, the language, the channels, the services, and the offered products and services. Understanding means that she constructed a precise mental model [3]), i.e. a semantic representation of a particular market-place which we call an inner logic. The performance of participating agents in an electronic market-place is correlated to their understanding of these structural elements. In addition to the inner logic agents use outer logics to express their inner logics in languages which can be used for communications. In general, the actions which can be taken by the addressee are described in the outer logic of the agent. This means that the content and the actions can be used by all agents who understand the outer logic of the agent (see Figure 2). Examples of outer logic are direct speech or bug reports of applications. For a message to be understood by any market participant, it must be transformed into a logic which is understood in this community. This logic is called transfer logic. Examples are e-mail on the basis of SMTP, HTML on the basis of http, mobile phone calls on the basis of GSM. These transfer logics wrap content into communication protocols which are accepted by the participating agents. If an agent understands the generic actions defined by each protocol he will be able to participate in this digital medium.

- Operator-driven-logical-space: a market-place introduces a new logic in terms of organisation, language, channels, and services (e.g. Ebay). Market participants are required to learn this logic before the can efficiently and effectively act on these markets (see Figure 2).

- User-driven-logical-space: the language of the market-place is translated into the language of each agent, i.e. it speaks her language so that she can participate with little adaptation needs (see Figure 3).

The first position represents logics of traditional physical or digital market-places. An agent $\mathrm{X}$ wants to sell a good by his market-place and expresses his inner logic $\mathrm{X}$ for this transaction in the outer logic $\mathrm{X}$ of this market-place. Because he designed this market-place by using his logic (e.g. amazon.com), the inner logic and the outer logic are almost identical. In electronic media the outer logic also defines the transfer logic to a potential customer $\mathrm{Y}$. If agent $\mathrm{Y}$ wants to interact with agent $\mathrm{X}$ via this market-place, she will have to translate the outer logic which she receives into her mental models, i.e. her inner logic. 
Figure 2 Operator-driven logical spaces in traditional electronic market-places

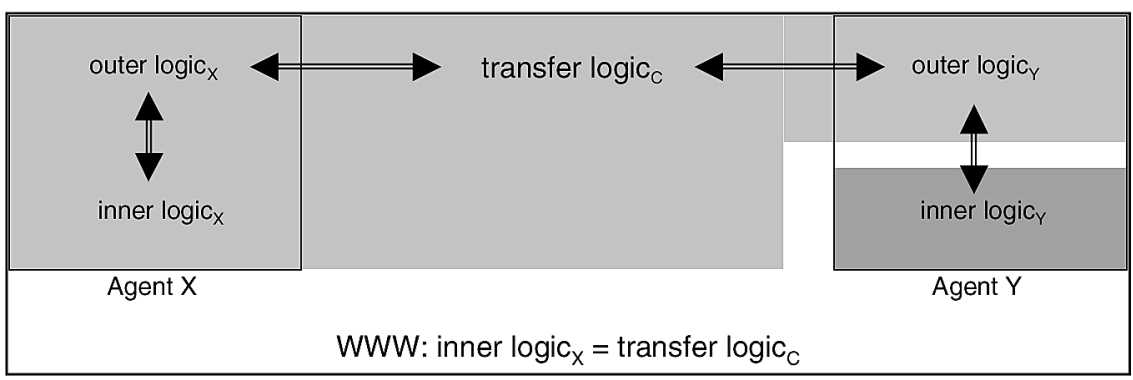

Figure 3 Logical spaces in personal business media

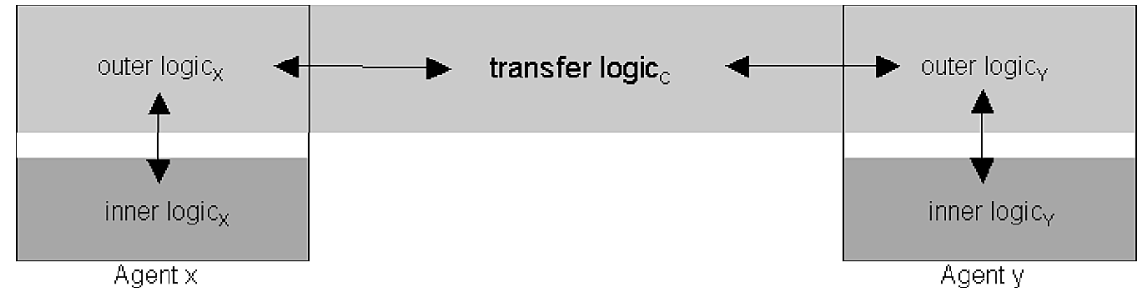

Modular Communication:

inner logic $=$ translate-by-logic (transfer $\operatorname{logic}_{\mathrm{C}}$ )

inner logic $=$ translate-by-logic $($ transfer logic $)$

By looking at the www it becomes obvious that this translation is left to the human being associated to agent $\mathrm{Y}$. She is required to translate offerings of bank, insurances, automotive companies, and travel agencies into her inner logic. Table 1 gives an example of a operator-driven cycle of communication in a traditional www market-place (website $\mathrm{X}$ ). It starts with agent $\mathrm{X}$ who issues his offers by transferring his logic to agent $\mathrm{Y}$ where she translates it into her logic and her response into the transfer logic which is defined by agent X. After step 6 the whole cycle starts over again.

The second position contains the rather extreme view that any market-place communication is adapted to the language and knowledge of each participant. Hence, products and services describe themselves in categories which are part of the participant's mental models. This requires that the content of messages, so called information objects, based on product and service descriptions in an electronic market-place, can be matched and translated into the agent's inner logic. Taking natural language descriptions as an extreme form of content, the content consists of syntactical, semantical, and pragmatical representations [18]. 
Table 1 Operator-driven market communication with modular market logics

\begin{tabular}{|c|c|c|}
\hline Agent X & Medium & Agent $Y$ \\
\hline $\begin{array}{l}1 \\
\text { Inner logic } \chi(\mu)= \\
\text { Outer logic } \chi(\mu)\end{array}$ & $\begin{array}{l}2 \\
\text { Transfer logic } C(\mu)= \\
\text { Outer logic } \chi(\mu) \\
\text { Channels } C=\text { website } \chi(\mu) \text {; } \\
\text { Protocol: general }\end{array}$ & $\begin{array}{l}3 \\
\text { Outer logic }(\mu)= \\
\text { Transfer logic } \chi(\mu)= \\
\text { Outer logic } \chi(\mu) \\
\text { Inner logic } \chi(\mu) \text { Translate- } \\
\text { by-human }(\text { transfer } \\
\operatorname{logic} \chi(\mu))\end{array}$ \\
\hline $\begin{array}{l}6 \\
\text { Inner logic } \chi(\mu)= \\
\text { Outer } \operatorname{logic} \chi(\mu)= \\
\text { Transfer } \operatorname{logic}{ }_{B}(\mu)=\text { Outer } \\
\operatorname{logic}_{Y}(\mu)\end{array}$ & $\begin{array}{l}5 \\
\text { Transfer } \operatorname{logic} B(\mu)= \\
\text { Outer } \operatorname{logic} C_{Y}(\mu)= \\
\text { Outer logic } \chi(\mu) ; \\
\text { Channels } C=\text { website } \chi(\mu) \text {; } \\
\text { Protocol: general }\end{array}$ & $\begin{array}{l}4 \\
\text { Transfer logic } \chi(\mu)= \\
\text { Outer logic }{ }_{Y}(\mu)= \\
\text { Translate-by-human(inner } \\
\operatorname{logic} \chi(\mu))\end{array}$ \\
\hline
\end{tabular}

The syntactical representation encompasses the grammatical encoding of a message which is matched by a lexicon with a semantical representation of the inner logic of the agent. For instance, for a financial layman the term 'shortfall risk' in a financial offering is translated into the more elaborated description 'the minimum number of years in which a positive return on investment is achieved with a probability of 95\%'. The analogue procedure is used if the agent responds to a message (see Table 2). This translation process is feasible if the logical structure of the transfer logic is not ambiguous. Generally speaking, because of its fuzziness natural language provides a weak fundament for formal transfer logics. Ambiguities in natural language lead to misunderstandings of communicating agents. Hence, formal representations of transfer logics are required which should be as open, simple, and well-structured as possible.

Table 2 Agent-driven market communication with modular market logics

\begin{tabular}{|c|c|c|}
\hline Agent $X$ & Medium & Agent $Y$ \\
\hline $\begin{array}{l}1 \\
\text { Outer logic } \chi(\mu)= \\
\text { Translate-by-logic(inner } \\
\text { logic } \chi(\mu))\end{array}$ & $\begin{array}{l}2 \\
\text { Transfer } \operatorname{logic}_{\mathrm{C}}(\mu)= \\
\text { Outer logic } \chi(\mu) \\
\text { Channels } \mathrm{C}=\text { micro channel; } \\
\text { Protocol: defined }\end{array}$ & 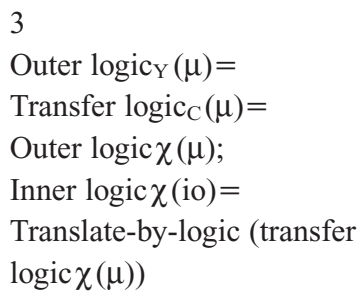 \\
\hline $\begin{array}{l}6 \\
\text { Inner logic } \chi(\mu)= \\
\text { Translate-by-logic }(\text { Outer } \\
\text { logic } \chi(\mu))= \\
\text { Translate-by-logic(transfer } \\
\left.\operatorname{logic}_{C}(\mu)\right)\end{array}$ & $\begin{array}{l}5 \\
\text { Transfer logic } \chi(\mu)= \\
\text { Outer logic }(\mu)= \\
\text { Outer logic } \chi(\mu)\end{array}$ & $\begin{array}{l}4 \\
\text { Transfer } \operatorname{logic}_{\mathrm{C}}(\mu)= \\
\text { Outer logic }(\mu)= \\
\text { Translate-by-logic (inner } \\
\operatorname{logic}_{Y}(\mu) \text { ); }\end{array}$ \\
\hline
\end{tabular}


Additionally the structures of the market-place, i.e, the organisational logic (roles with rights and obligations) and market services available in this situation, need to be translated. If an agent's view on an electronic market-place is defined by his independent outer logic respectively inner logic, we call it a personal business medium (see Figure 4). The main difference between both positions is that the transfer logic in position 1 is dependent on a particular inner logic (agent X - traditionally the operator) and that it is mainly independent from the inner logic of each agent in position 2 . If the transfer logic is based on a formal representation it can be (semi-) automatically translated into and from inner logics (function 'translate-by-logic').

Figure 4 Personal media

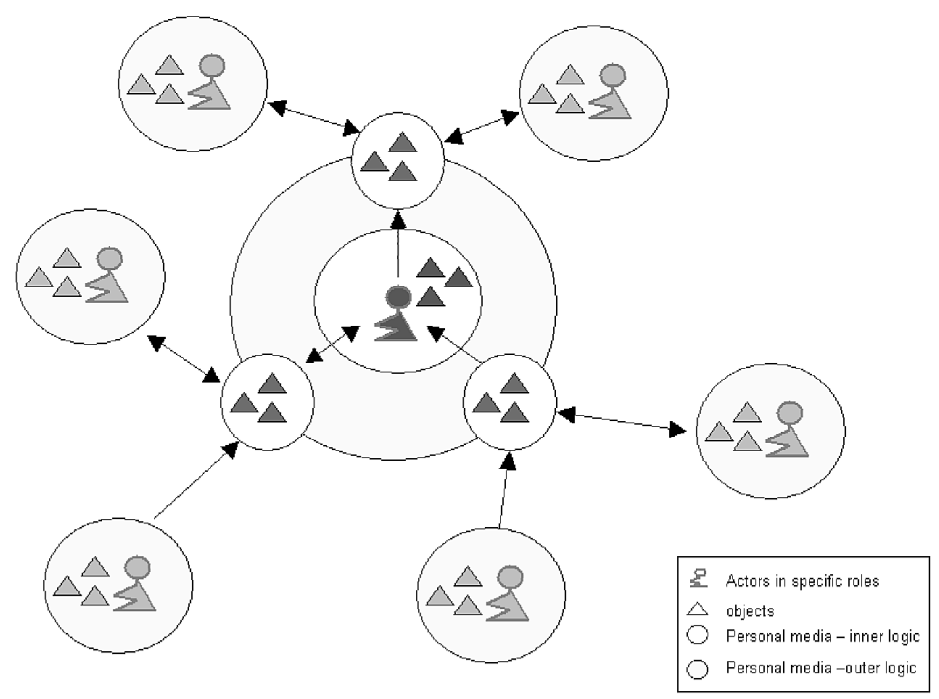

Beside the issues discussed on natural language processing, position 2 assumes a precise representation of the agent's role, intentions, and knowledge. Because these translations require deep personal information on the agent, the major part of the translation is done within the private scope of the agent, i.e. his personal medium. This could be done by a trusted third party or by the agent itself.

\section{Personal business media}

Efficient and effective electronic market-places depend on open, digital and extensible transfer logics. Any agent, be it a whole organisation or a single agent, can participate in this market if it will support the transfer logic. This should be made clear with an example. Mrs Smith (teacher) accesses amazon.com and is interested in a book by Kofi Annan. When she accesses the abstract of this book, terms in this abstract will be annotated with glossary items which are defined in her private teacher's dictionary. For instance, the term 'globalisation' is translated to her by a more general and comprehensive description. In more advanced digital media you could imagine translating the whole abstract into a description by using sophisticated natural language processing systems. 
The concept of personal media is an electronic place of interaction, i.e. an electronic medium, which is generated according to the intentions and needs of single agents, which in many cases take the role of a customer. Therefore personal media can be generated and deleted at any time and for any defined type of communicational or business need (see Figure 4). Personal media route resources, such as goods, problem solutions and information, via media channels to an agent and agents exchange messages with other agents in a mutually accepted transfer logic. The communication is controlled by a media protocol. When a message arrives at an agent he accepts or rejects it. Acceptance leads to an integration in its outer logic memory. At a given time the agent processes this message by translation into its inner logic. For human beings this means the integration of the content of a message into her mental models. Messages, represented in inner logics, can be stored, modified, merged, deleted, or used for composing new messages. Personal media can be used for exchange of information or performance of transactions. The first, we call personal knowledge media and the latter personal business media.

In order to implement business media an open and modular architecture is required in which business services can be plugged into with little cost in business, technology, marketing and communications. Before we will present micromarkets and technical channel architecture for personal media we will briefly discuss a representational media framework.

\section{Representation of the logical flow in electronic media}

Personal business media depend on the concept of personal media which is based on the media model [6]. Personal business media functionally bind an actor X to a business media channels $c \epsilon$; according to a specific market situation $\Gamma$ by a function btc(). A message $\mu$ which is transported via a channel $c \epsilon$ needs to be translated into the associated transfer logic. Hence, the representation of the inner logic needs to be translated into an outer logic, then into the transfer logic and back again into the outer logic and inner logic of the recipient. The role of the participant can be represented by a relation $\mathrm{r}(\Gamma, \mathrm{x})$. Therefore the logical flow of communication can be represented by a media relation $\mathrm{R}_{\Gamma}$ as follows:

$\mathrm{R}_{\Gamma}\left(\operatorname{LS}_{\Gamma}(\mathrm{ol}(\mu, \mathrm{x}), \mathrm{il}(\mu, \mathrm{x})), \mathrm{r}(\Gamma, \mathrm{x}), \operatorname{btc}\left(\Gamma, \mathrm{c}_{\varepsilon}, \mu, \mathrm{x}\right)\right)$ with:

- $\quad \mathrm{R}_{\Gamma}$ is a relation of a personal business medium $\Gamma$ which binds a message $\mu$ in logical space $\mathrm{LS}_{\Gamma}$ of agent $\mathrm{x}$ according to her role $\mathrm{r}(\Gamma, \mathrm{x})$ to a communication channel btc $\left(\Gamma, \mathrm{c}_{\varepsilon}, \mu, \mathrm{x}\right)$.

- $\mathrm{LS}_{\Gamma}$ : representation of the logical space corresponding to situation $\Gamma$. Simple personal business media $\mathrm{LS}_{\Gamma}$ consists of a glossary, relationship sets between terms, and a query language. In more advanced representations, the glossary is replaced by semantic relations. For instance, these semantic relations can be implemented on semantic representation frameworks such as RDF.

- $\quad \mu: \mu$ consists of a set of information objects $\iota_{\alpha}$

- $\quad$ ol $(\mu, x)$ : outer logic of agent X message $\mu$

- $\quad$ il $(\mu, x)$ : inner logic of agent $X$ message $\mu$

- $\operatorname{btc}\left(\Gamma, c_{\varepsilon}, \mu, x\right)$ : Relation 'bound-to-channel' of agent $\mathrm{x}$ in a market $\Gamma$ when agent $\mathrm{x}$ intends to receive or transmit a message $\mu$ via channel $c_{\varepsilon}$.

This relation $\mathrm{R}_{\Gamma}$ transforms the message according to its context (see Figure 5). 
Figure 5 Transformation of media relation R

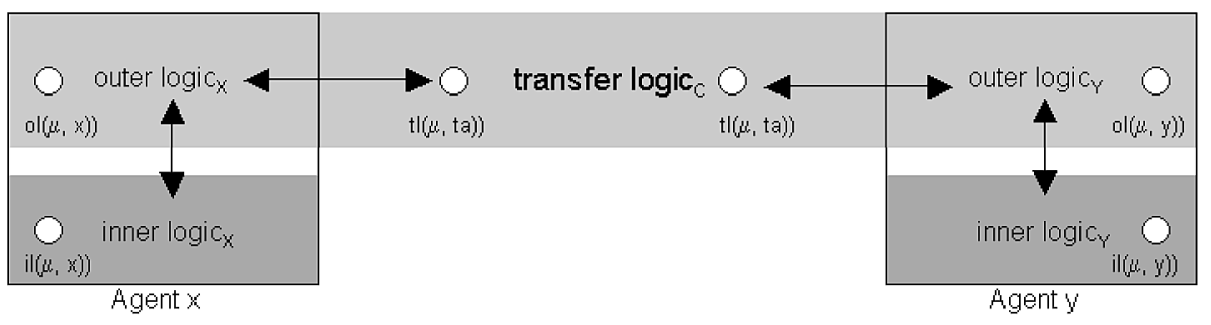

$R_{\Gamma}\left(\operatorname{LS} S_{\Gamma}(0 \mid(\mu, x), i(\mu, x)), r(\Gamma, x), \operatorname{btc}\left(\Gamma, c_{z}, \mu, x\right)\right)$

$\mathrm{R}_{\Gamma}\left(\mathrm{LS} \mathrm{S}_{\Gamma}(0 \mid(\mu, y), \mathrm{il}(\mu, y)), \mathrm{r}(\Gamma, y), \operatorname{btc}\left(\Gamma, \mathrm{c}_{\mathrm{z}}, \mu, y\right)\right)$

Analogue to the message transfer agent in the SMTP protocol, the personal media model uses a message transfer agent $t a$ to deliver messages via media channels to agents. Hence, relation $\mathrm{R}$ is used to map the outer logic of an agent with the transfer logic $t l$ of a market-place $\Gamma$. From these relations, we can derive market-place protocols which can be used for open, modular, and recursive market-place structures.

\section{Micromarkets}

Based on the personal media model we have designed a technical channel architecture for personal media, called micromarkets. Micromarkets implement media channels which can be plugged into personal media of single agents for transporting messages _ from sending agents, via transfer agents to receiving agents and back again. Hence, micromarkets can be used to deliver structured market-place messages between agents according to a mutually accepted communication protocol which means that micromarkets implement the channel architecture for personal business media. Beside the infrastructure on which micromarket communications are performed, micromarkets consist of two entities (see Figure 6):

1 Message: a message is a container for a set of information objects. Analogue to the structure of information objects [19], the structure of messages are attribute-value pairs.

2 Media protocol: a media protocol is a representation of a particular type of market communication. Examples are auctions, shopping, contract and negotiations. It is represented by a general graph. A protocol of a market-place $\Gamma$ defines what role is required by an agent to be allowed to receive or send a message $\mu$ to other agents by a channel $\mathrm{c}_{\varepsilon}$. Therefore a media protocol is a programming language for market communications. Attribute-value pairs of messages are bound to values during a process of communication by actions of participating agents as described in the protocol. Protocols are based on sequences of assertions, if-then-else branches and while-loops. 
Figure 6 Micromarkets

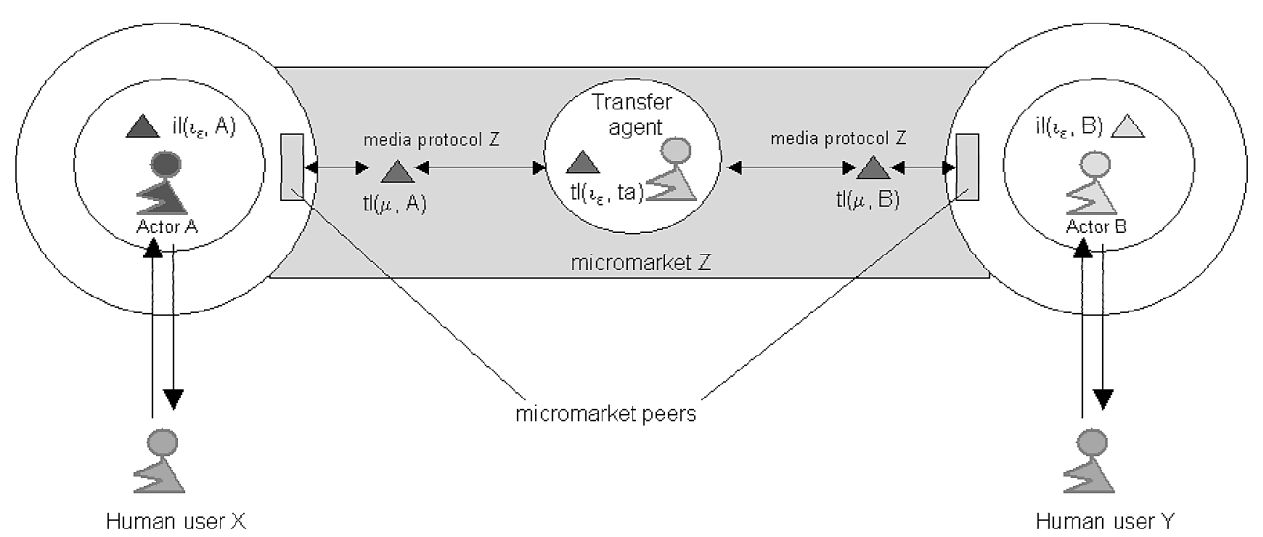

At the beginning of a market communication a message consists of all attribute-value pairs which represent the prototypical initial structure for this type of communication. This means all values which are typically assumed to be mutually agreed on in this market situation. During a market communication a message can be enriched with new attribute-value pairs. They will only have impact on the communication if they are mutually accepted by all participants. If a market communication ends with an agreement the message becomes a contract, otherwise it simply becomes a protocol of this market communication.

Micromarkets can be implemented on lower level transport layers such as messaging services (for instance Java Messaging Service), on e-mail or on higher-level layers such as SOAP-enabled infrastructures. Two generic types of agents are to be distinguished:

1 User agent: each market participant is attached to a user agent which can be seen as his avatar in an electronic market. A user agent interacts with messages as defined by the media protocol and his role, which he is allowed to take in a particular market communication.

2 Transfer agent: each communication on a micromarket has a unique transfer agent who interacts with user agents. A transfer agent delivers messages between user agents according to the rules defined in the protocol. He is not allowed to read any content of a message but evaluates control information according to the protocol.

Market communications can be interconnected so that networks of personal business media emerge. For instance, intermediaries typically sign contracts with customers if they negotiated contracts with their suppliers beforehand. A discussion of micromarket networks goes beyond the scope of this article. A micromarket delivers messages between user agents according to a defined personal media protocol. It does not handle the translation process between transfer logics of a message $\mu$ and outer logics, respectively, inner logics.

Transfer agents support personal media protocols which are broadcast, point-to-group, or point-to-point. Broadcast and point-to-group communications are in particular used during the information and intention phase of a market communication. 
During the negotiation phase point-to-group communications or point-to-point communications are used. The settlement phase is typically dominated by point-to-point communications. Many-to-many communications are currently not supported by micromarkets.

The current implementation of the micromarket infrastructure is a peer-to-peer-based Java messaging system which uses JNDI for directory services and XML/XML Schema for the representation of messages and media protocols. Micromarket peers are implemented in Java and deliver XML-based messages to user agents which support the FIPA protocol or to generic connectors based on servlets or web service infrastructures, e.g. UDDI. The micromarket infrastructure is in use in environments for supply chain management, corporate communication, flight booking markets, project staffing, and human resource/job markets. It is currently tested for distributed knowledge media.

\section{Managerial implications}

Napster and WikiWiki [21] are first representatives of interlinked personal information media. They lack underlying business models but they made visible to a broad audience how information can be controlled by individuals and shared according to individual rules. Napster imposes a single semantic space onto its community whereas WikiWiki leaves translations between personal information media to its single user. Even Ebay is extending its business model by shop-in-the-shop models to individualised peer-to-peer-like electronic market-places.

These infrastructures will pave the path for electronic market-places based on personal business media which will enable any group of individuals to start altruistic, reputation-based or commercial networks for the exchange and trade of goods, information and services. Examples are networks for expertise/consulting, legal advice, support, learning, recruiting, spare parts, baby sitting and (used) cars. Any person, commercial or non-profit organisation who obeys the particular protocol of an electronic market-place will start her own business. This will be enabled by modular, recursive and distributed electronic market-places with minimal costs for coordination. Those electronic market-places might only exist for a short period of time (e.g. Olympic Games) or a long period of time (e.g. spare parts).

Napster is a role model for how quickly a multi-million world-wide community understands, accepts and applies a peer-to-peer-based design. The right design on top of personal business media architectures might unleash enormous business potentials which would lead to redesigns of large parts of existing economic systems.

\section{Summary and open issues}

Models for electronic markets have been developed for years. But the termination of most of the promising commercial B2B market-places indicate that there are still some open questions to be solved. With personal business media we introduced a model for user-centered electronic market-places. Via media channels market messages are dynamically routed to and translated into the language of a participant. The communication between participants is managed by media protocols. With micromarket we briefly described an implementation of the personal media model. Compared to traditional 
centralised electronic market-places, micromarkets provide a lean, open, modular, and flexible channel infrastructure for any type of electronic market-place.

As generally described in this article, the framework for personal media has been worked out in detail. Currently we are working on a detailed formal specification and implementation which includes the generic translation process between different logical spaces. Furthermore we will extend our analysis in the area of personal knowledge media.

\section{References}

1 Schmid, B.F. (2000) 'Elektronische Märkte', in R. Weiber (Hrg.) Handbuch Electronic Business: Informationstechnologien - Electronic Commerce - Geschäftsprozesse, Wiesbaden: Gabler Verlag, Sept. 2000, pp.181-207.

2 Malle, B.F., Moses, L.J. and Baldwin, D.A. (2001) (Eds.) Intentions and Intentionality: Foundations of Social Cognition, Cambridge, MA: MIT Press.

3 Johnson-Laird, P. (1983) Mental Models, Cambridge University Press.

4 Schmid, B.F. (2002) Medien- und Kommunikationsmanagement, Buch Belz-Bieger.

5 Schmid, B.F. and Lindemann, M. (1998) 'Elements of a reference model electronic markets', 31st Annual Hawaii International Conference on Systems Science (HICCS '98), Hawaii, Jan 1998.

6 Segev, A., Gebauer, J. and Faeber, F. (1999) 'Internet-based electronic markets', International Journal of Electronic Markets, Vol. 9, No. 3.

7 Bakos, J.Y. (1998) 'The emerging role of EM on the internet', Communications of the ACM, Vol. 41, No. 8, pp.7-20.

8 Kotler, P. and Armstrong, G. (1991) Principles of Marketing, London: Prentice-Hall International Editions, Fifth Edition.

9 Moran, W. (1990) 'Brand preference and the perceptual frame', Journal of Advertising Research, Oct/Nov, pp.9-16.

10 Fill, Ch. (1995) Marketing Communications, London: Prentice Hall.

11 Wright, P. (2002) 'Market-place metacognition and social intelligence', Journal of Consumer Research, Vol. 28.

12 Grieger, M. (2003) 'Electronic market-places: a literature review and a call for supply chain management research', European Journal of Operational Research, Vol. 144, pp.280-294.

13 Bakos, J.Y. (1991) 'A strategic analysis of EM', MIS Quarterly, Vol. 15, No. 4, pp.295-310.

14 Kaplan, S. and Sawhney, M. (2000) 'E-hubs: the new B2B market-places', Harvard Business Review, pp.97-104.

15 Dai, Q. and Kauffmann, R.J. (2000) 'Business models for internet based e-procurement systems and B2B EM: an exploratory assessment', 34th Hawaii International Conference on Systems Science (HICSS34).

16 Schmid, B.F. (2001) 'What is new about the digital economy?', International Journal of Electronic Markets JEM, Vol. 11, No. 1, pp.44-51.

17 Bradley, D.B. and Peters, D. (1997) 'Electronic market-places: collaborate if you want to compete', 42nd World Conference International Council for Small Business, San Francisco.

18 Levelt, W.J.M. (1989) Speaking: from Intention to Articulation, MIT Press.

19 Information objects consist of at least eleven layers for content layer, context, community, domain, history, evaluation, method, transition, business, legal, security (see [21]).

20 Maass, W., Eickhoff, W.-C., Stahl, F. and Schäfer, M.-F. (2003) 'Information objects in knowledge trading and sharing media', forthcoming.

21 http://www.wikipedia.org/wiki/WikiWiki 